\title{
Yığma Binalarda Deprem Performansının Belirlenmesi (Bayburt Korkut Ata Lisesi Örneği)
}

\author{
Determination of Earthquake Performance in Masonry Buildings \\ (Bayburt Korkut Ata High School Example)
}

\author{
Ömer CAN ${ }^{1, a}$, Halime YILDIZOĞLU* ${ }^{2, b}$ \\ ${ }^{1}$ Bayburt Üniversitesi, Mühendislik Fakültesi, Inșaat Mühendisliği Bölümü, 69000, Bayburt \\ ${ }^{2}$ Bayburt Üniversitesi, Fen Bilimleri Enstitüsü, İşaat Mühendisliği ABD, 69000, Bayburt
}

\author{
• Geliş tarihi / Received: 17.01.2018 • Düzeltilerek geliş tarihi / Received in revised form: 30.04.2018 • Kabul tarihi / Accepted: 14.05 .2018
}

\begin{abstract}
$\ddot{O} z$
Türkiye'de tarihi ve kültürel değeri olan birçok yapı bulunmaktadır. Bu yapılar farklı zaman ve kültürlerin birikim ve tekniklerini yansıtmaları bakımından büyük önem taşımaktadırlar. Günümüz teknolojisi ile inşa edilen betonarme ve çelik yapıların performansının gelişmiş sayısal metotlarla ayrıntılı olarak ortaya koymak mümkündür. Lakin tarihi yığma yapıların içerdiği süreksizlikler ve değissen malzeme özelliklerinden dolayı yapısal performansının belirlenmesinde ve yorumlanmasında zorluklarla karşılaşılabilmektedir. Bu çalışmada; Bayburt ili merkezinde bulunan, 1944-1947 yılları arasında inşa edilen, Korkut Ata Lisesi’nin yapım tekniği, malzeme özellikleri ve konum özellikleri hakkında bilgiler derlenmiștir. Yapıda gözlemlenen mevcut problemler belirlenmiştir. StatiCAD-Yığma programı kullanılarak 2007 Deprem Yönetmeliği ve 2013 Riskli Yapılar Yönetmeliği esasları dikkate alınarak yapının performans analizini yapmak amaçlanmıştır. Yapılan analizlere paralel olarak taşıyıcı sistemin yapısal performansı değerlendirilmiştir.
\end{abstract}

Anahtar kelimeler: Performans Analizi, StatiCAD- Yığma, Yığma Yapı

\begin{abstract}
There are many buildings which are historical and cultural values in Turkey. These structures are of great importance in terms of reflecting the accumulation and techniques of different times and cultures. It is possible to elaborate the performance of reinforced concrete and steel structures constructed with today's technology with advanced numerical methods. But difficulties can be encountered in determining and interpreting the structural performance due to the discontinuities and the changing material properties of the historic agglomerations. In this study; The construction technique, material properties and location features of Korkut Ata High School, which was built between 1944-1947 in Bayburt province center, was compiled. The existing problems observed in the structure have been identified. Using the StatiCAD-Masonry program, it was aimed to perform the performance analysis by taking into account the principles of the 2007 Earthquake Regulation and the 2013 Risky Buildings Regulation. Parallel to the analyzes carried out, the structural performance of the carrier system was evaluated.
\end{abstract}

Keywords: Performance Analysis, StatiCAD-Masonry, Masonry Building

\footnotetext{
*b Halime YILDIZOĞLU; halimeyildizoglu91@gmail.com; Tel: (0554) 988 1338; orcid.org/0000-0001-5888-285X

${ }^{a}$ orcid.org/0000-0002-8182-2967
} 


\section{Giriş}

Ülkemizin büyük bir bölümü aktif fay hatları üzerinde bulunmaktadır. Son 30 yılda ülkemizde 7 ve üzeri büyüklügünde birçok deprem meydana gelmiştir. Yapıların bu depremlere karşı yeterli dayanım sağlaması can ve mal kaybının olmaması için zorunludur (Atabey, 2011; Düzgün vd., 2015a).

İnsanlık tarihinin başlangıcından günümüze kadar binlerce y1llık uygarlık tarihi içinde insanın doğrudan veya doğa ile birlikte yarattığı değerler, bugün "kültürel ve doğal miras" olarak adlandırılır. Bu değerlerin korunması, çağımızda insanlığın ortak sorunudur (Aköz ve Yüzer, 2009).

Birçok medeniyete ev sahipliği yapmış olan topraklarımız, tarihi eserler yönünden çok zengindir. Tarihi ve anıtsal yapılar toplum için kültürel miras olarak kabul edilmektedir. Bu tarihi mirasın korunması ve geleceğe en iyi şekilde aktarılmas1 üzerinde hassasiyetle durulmas1 gereken bir konudur (Aköz, 2008; Arıcan, 2010).

Tarihi yapılar yı̆̆ma yapı tekniği ile inşa edilmişlerdir. Günümüzde inşa edilen betonarme binaların ekonomik ömürlerinin yaklaşık 50 yıl olduğu düşünülürken, tarihi yapıların yüzyıllar boyunca ayakta kalarak günümüze ulaştığı görülmektedir. $\mathrm{Bu}$ durum tarihi yı̆̆ma yapıların yapısal özelliklerinin ve deprem etkisi altındaki davranışlarının daha iyi anlaşılması gerektiğini göstermektedir (Düzgün vd., 2015b).

Deprem olasılığının fazla olduğu bölgelerde, her bir tarihi yapının ayrı ayrı incelenip, yapısal davranış ve deprem performansının belirlenmesi gerekmektedir. Yapı malzemesinin dayanımındaki düşüşler, yapıda zamana bağlı deformasyonlar, zemin oturmaları, düzensiz yükleme doğal afetler, olumsuz çevre koşulları, ilgisizlik gibi nedenlerle bu yapıların deprem dayanımları kritik bir noktaya gelmiş olabilmektedir. Betonarme ve çelik yapıların gerek düşey gerek yatay yükler altında nasıl davrandığ 1 yılların bilgi birikimi sonucu belli bir doğrulukta hesaplanabilmekte, matematiksel olarak ifade edilebilmektedir. Yığma yapıların düşey ve özellikle yatay yükler altındaki davranışı betonarme yapılarla kiyaslandığında, daha belirsizdir. Yığma yapıların içerdiği süreksizliklerden dolayı özelliklerinin farklı yönlerde değişiklik göstermesi ve malzeme kalitesinin değişebilmesi nedeniyle yapısal davranışlarının yorumlanmasında güçlükle karşılaşılabilmektedir (Dabanlı, 2008; Sayın, 2009; Kılıç vd., 2013; Chamaky, 2014).
Tarihi yığma yapıların önce sistematik düzen içerisinde deprem güvenliği açısından değerlendirilmesi, sonra da anlamlı bir öncelik sıralaması içinde depreme karşı güvenli duruma getirilmesi gerekmektedir (Sallı, 2005).

Tarihi yığma yapıların mevcut yükler altında ve ileride oluşması muhtemel deprem hasarlarına karş1 yapısal davranışının bilinmesi için izlenilebilecek yolda;

- Birinci aşama, değerlendirilecek yapı hakkında bilgi edinilmesidir. Bunun için yapının tarihi gelişim süreci detaylı olarak araştırılmalı ve bölgesel veriler toplanarak yapının hangi etkilere maruz kalabileceğinin belirlenmesidir.

- İkinci aşama, yapının röleve çizimleri çıkarılarak, sistem geometrisini en iyi şekilde temsil edecek yapı modelinin oluşturulmasıdır.

- Üçüncü aşama, yapının maruz kalabileceği yüklerin belirlenerek model üzerinde uygulanması için yapının kendi ağırlığı ve dinamik yükler etkisi altındaki davranışının analiz edilmesidir.

- Dördüncü aşama ise yapı analiz sonuçlarına bakılarak hangi bölgelerde hasarlar oluşabileceği ve ortaya çıkan gerilmelerin izin verilen maksimum değerlere göre kıyaslanmasidır (Çal ve Şahin, 2015).

Bu çalışmada, Bayburt ilinde bulunan Korkut Ata Lisesi'nin röleve çalışması yapılmıştır. Yapılan ölçümler AutoCAD Programına aktarıldıktan sonra analizler için StatiCAD-Yığma Programı kullanılmıştır. StatiCAD- Yığma Programında performans analizleri yapılarak, elde edilen sonuçlar değerlendirilmiştir.

\section{Korkut Ata Lisesi}

Bayburt ili Türkistan Caddesi Lise Sokakta bulunan Korkut Ata Lisesi 1943-1946 y1lları arasında inşa edilmiştir. Sonraki yıllarda bu binaya bir ek bina yapılmıştır. Bu ek binanın yapım tarihi hakkında kesin bilgi elde edilmemiştir. Binanın onarım geçiren ve kullanım değişikliği olan bölümleri olmuştur. Yapılan incelemelerde sonradan yapılan değişikliklerin, binanın taşıyıcı sistemini etkilemeği belirlendiğinden, çizim ve hesaplarda dikkate alınmamıştır. Zemin ve bir normal kattan oluşan binanın iç ve dış duvarları Bayburt Taşı olarak bilinen doğal taş malzeme kullanılarak inşa edilmiştir. Dış cephe sıvanmıştır. Sadece ön cephe Bayburt Taşı ile kaplanmıştır. 


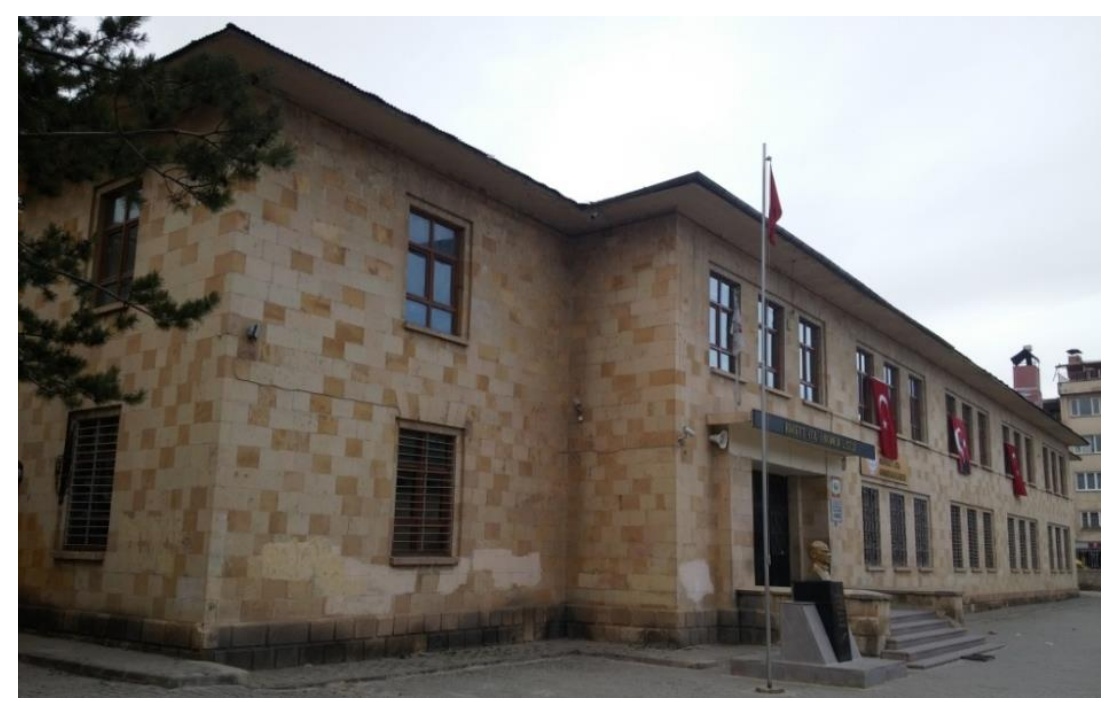

Şekil 1. Korkut Ata Lisesi Sol Görünüş (2016)

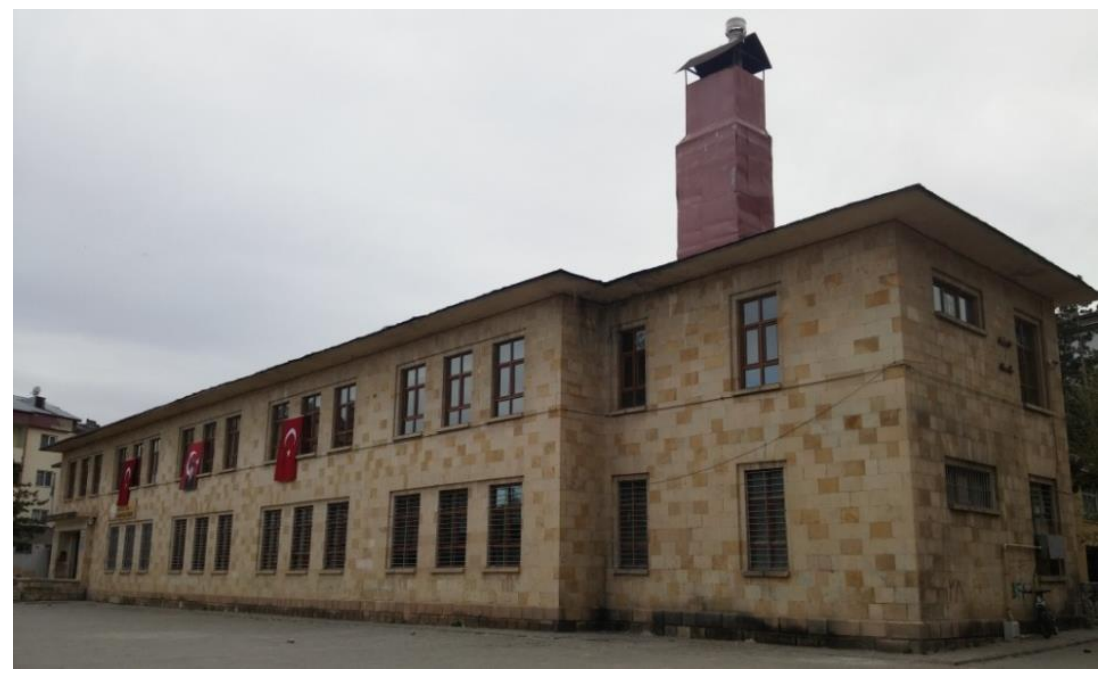

Şekil 2. Korkut Ata Lisesi Yan Görünüş (2016)

\subsection{Malzeme ve Özellikleri}

Yapılan çalışmalarda doğal taşın basınç kuvvetlerine karşı dayanıklı, çekme kuvvetlerine karşı dayanımının düşük olduğu ve yığma yapı elemanlarının dayanım, dayanıklılık ve diğer malzeme özelliklerinin taş, harç, taşın işleniş biçimi ile birleşim dokusuna bağl1 olduğu belirtilmektedir. Tarihi yığma yapıda kullanılan malzemelerin özelliklerini belirlemenin mümkün olmadığ 1 durumlarda, kullanılan malzemelerin özellikleri geçmiş çalışmalardan alınabilmektedir veya 2007 Deprem Yönetmeliğinde belirtilen malzemelerin dayanım ve fiziksel özellikleri kullanılabilmektedir (Can ve Ünay, 2012; Çobanoğlu, 2014; Arslan, 2016).

Tarihi yı̆̆ma yapılarda kullanılan doğal yap1 taşlarının ortalama fiziksel ve mekanik özellikleri Tablo 1 ve Tablo 2'de verilmiştir.
Tablo 1. Doğal yapı taşlarının ortalama fiziksel özellikleri (Ünay, 2002)

\begin{tabular}{|l|c|c|c|c|}
\hline $\begin{array}{l}\text { Taşın } \\
\text { Cinsi }\end{array}$ & $\begin{array}{c}\text { Basınç } \\
\text { Dayanımı } \\
\left(\mathbf{N} / \mathbf{m m}^{2}\right)\end{array}$ & $\begin{array}{c}\text { Kayma } \\
\text { Dayanımı } \\
\left(\mathbf{N} / \mathbf{m m}^{2}\right)\end{array}$ & $\begin{array}{c}\text { Çekme } \\
\text { Dayanımı } \\
\left(\mathbf{N} / \mathbf{m m}^{\mathbf{2}}\right)\end{array}$ & $\begin{array}{c}\text { Elastisite } \\
\text { Modülü } \\
\left(\mathbf{N} / \mathbf{m m}^{2}\right)\end{array}$ \\
\hline Granit & $30-70$ & $14-33$ & $4-7$ & $3 \times 10^{3}-55 \times 10^{3}$ \\
\hline Mermer & $25-65$ & $9-45$ & $1-15$ & $25 \times 10^{3}-70 \times 10^{3}$ \\
\hline Kireçtaş1 & $18-35$ & $6-20$ & $2-6$ & $10 \times 10^{3}-55 \times 10^{3}$ \\
\hline Kumtaş1 & $5-30$ & $2-10$ & $2-4$ & $13 \times 10^{3}-50 \times 10^{3}$ \\
\hline Kuvars & $10-30$ & $3-10$ & $3-4$ & $15 \times 10^{3}-55 \times 10^{3}$ \\
\hline Serpatin & $7-30$ & $2-10$ & $6-11$ & $23 \times 10^{3}-45 \times 10^{3}$ \\
\hline
\end{tabular}


Tablo 2. Doğal taş mekanik özellikleri için yapılan kabuller (Durutürk, 2012)

\begin{tabular}{|c|c|c|c|}
\hline $\begin{array}{l}\text { Eleman } \\
\text { Tipi }\end{array}$ & $\begin{array}{l}\text { Elastisite } \\
\text { Modülü } \\
\left(\mathbf{N} / \mathbf{m m}^{2}\right)\end{array}$ & $\begin{array}{c}\text { Özgül } \\
\text { Ağırlık } \\
\left(\mathbf{k N} / \mathbf{m}^{3}\right)\end{array}$ & $\begin{array}{c}\text { Poisson } \\
\text { Oranı }\end{array}$ \\
\hline $\begin{array}{l}\text { Taş } \\
\text { Duvarlar } \\
\text { (Harç ile } \\
\text { Birlikte) }\end{array}$ & 450 & 24 & 0.2 \\
\hline
\end{tabular}

\subsection{Korkut Ata Lisesi’nin Modellenmesi}

Korkut Ata Lisesi'nin mevcut durum projelerinin yetersiz olmas1 sebebiyle, öncelikle röleve çalışması yapılmıştır. Binanın doğu giriş cephesi $60.50 \mathrm{~m}$, kuzey cephesi $27.60 \mathrm{~m}$ 'dir. Yap1 ön cepheden bakıldığında dikdörtgen bir geometriye sahiptir. Kuzey ve güney cephede, kuzeyde kömürlük ve kalorifer dairesi, güneyde merdiven dairesi mevcuttur. Binanın arka cephesine iki kısımdan derslikler yerleştirilmiştir.

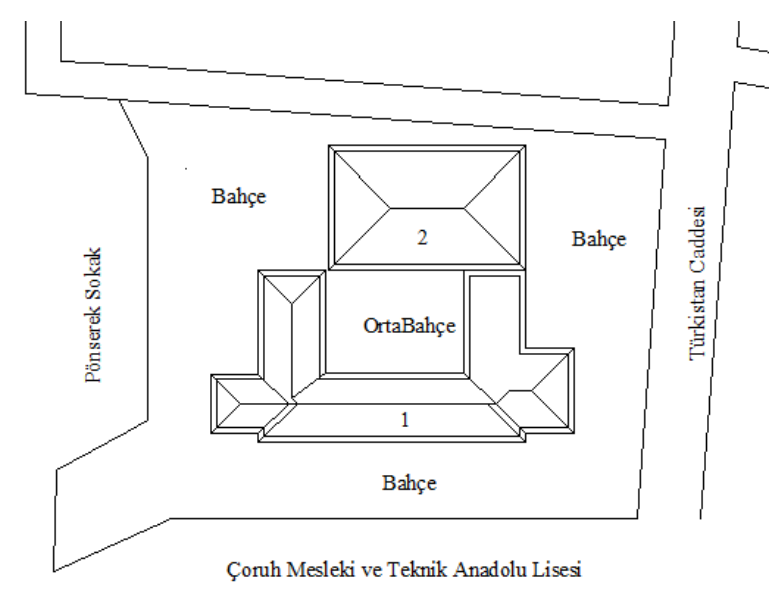

Şekil 3. Korkut Ata Lisesi'ne Ait Kroki

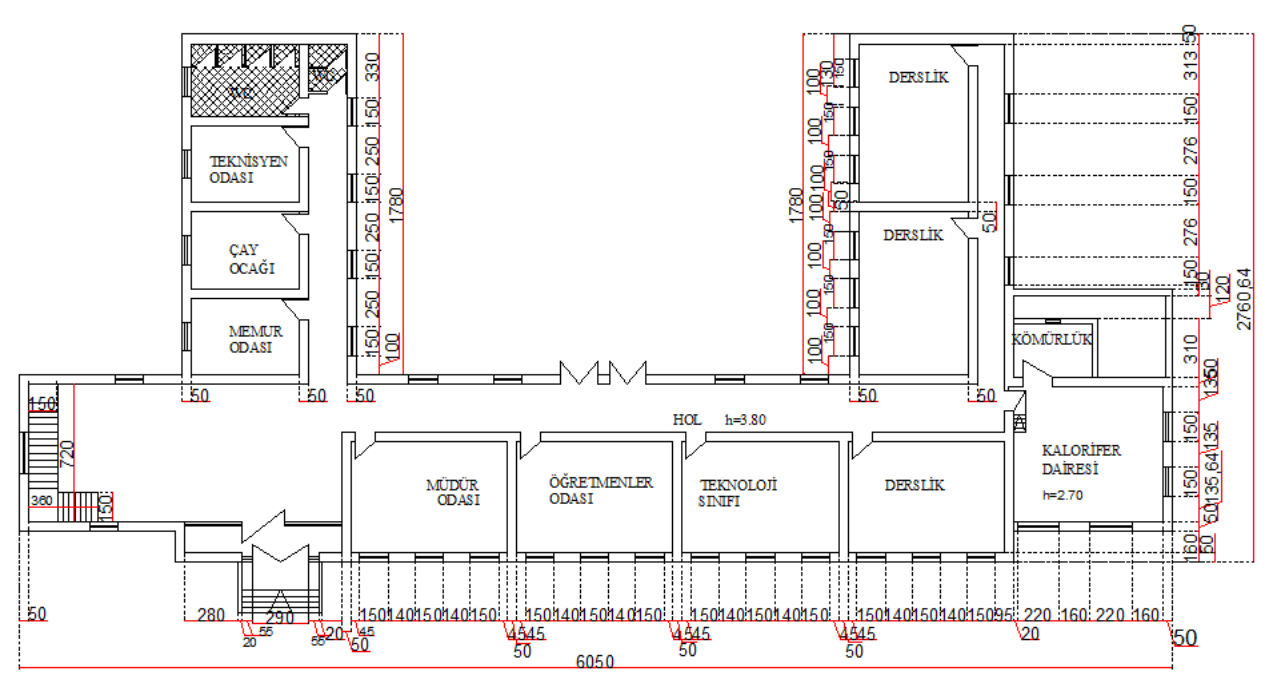

Şekil 4. Korkut Ata Lisesi’ne Ait Röleve Örnekleri (Zemin Kat)

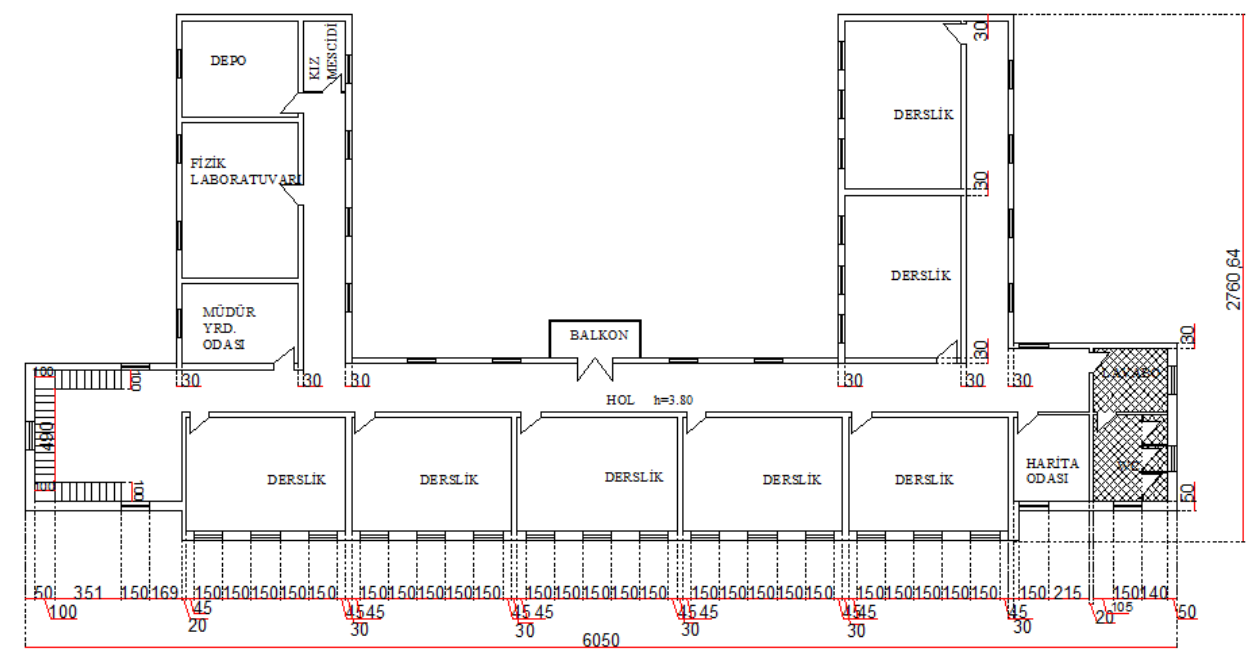

Şekil 5. Korkut Ata Lisesi’ne Ait Röleve Örnekleri (1. Kat) 
$\mathrm{Bu}$ çalışmada, tarihi yapının mevcut ölçülerine uygun şekilde modellenmesi için StatiCADYığma Programı kullanılmıştır. StatiCAD-Yığma Programı depreme dayanıklı yapı tasarımı için geliştirilen, yığma yapıların statik analizini yapan programdır. $\mathrm{Bu}$ program ile yeni yapiların projelendirilmesi yapıldığ 1 gibi mevcut yapıların deprem performans analizleri güçlendirmesi yapılabilmektedir. 2007 Deprem Yönetmeliği esaslarına veya 2013 Riskli Yap1 Tespit Yönetmeliği'ne uygun olarak mevcut binaların performans analizleri yapılabilmektedir.

Korkut Ata Lisesi'nin boyutlandırılmasından önce yapıya ait zemin değerleri, etrafında inşa edilmiş son dönem yapılarının zemin etüt raporları incelenerek belirlenmiştir. Bu alınan zemin etüt raporlarında verilen değerler birbirine yakın bulunmuştur. Bunlardan okul binasının en yakında bulunan binanın zemin etüt raporu referans alınmıştır. Bu değerler Tablo 3'de verilmiştir.
Yapının boyutlandırılmasında gerçek malzemeye en uygun malzeme ile boyutlandırma yapılmaya çalışılmıştır. Zemin ve bir normal kattan oluşan yapının döşemesi betonarmedir. Düşey ve yataydaki hatıllar gerçek boyutlarına uygun olarak modellenmiştir. Betonarme döşeme için beton sinıfi $20 \mathrm{MPa}$ alınırken donatı sinıfi S 220 alınmıştır.

Analiz yaparken gerekli olan yük kombinasyonları Tablo 4'de verilmiştir. 2007 Deprem Yönetmeliğinin 5. bölümünde verilen yığma binalar için depreme dayanıklı yapı tasarım kuralları incelendiğinde Tablo 5 'teki veriler elde edilmiş ve program ayarları buna göre yapılmıştır.

Elde edilen tüm verilerle birlikte Korkut Ata Lisesi'nin modellenmesi yapılmıştır. Binanın oluşturulan modeline ait görünüşler Şekil 6, Şekil 7 ve Şekil 8'de verilmiştir.

Tablo 3. Korkut Ata Lisesi'nin StatiCAD-Yığma Programına Aktarılabilmesi için Gerekli Değerler

\begin{tabular}{|c|c|}
\hline Zemin Grubu & $\mathrm{C}$ (Orta sık1 kum, Çakıl) \\
\hline$\sigma_{\text {zem }}\left(\right.$ Zemin Emniyet Gerilmesi $\left.t / \mathrm{m}^{2}\right)$ & 18 \\
\hline Standart Penetrasyon Değeri & $10-30$ \\
\hline BHA (Beton Birim Hacim Ağırlı̆̆ $(\mathrm{kg} / \mathrm{m} 3))$ & 2500 \\
\hline Rölatif S1k1lık & $\% 35-65$ \\
\hline Kayma Dalgası Hızı & $200-400 \mathrm{~m} / \mathrm{s}$ \\
\hline Yerel Zemin Sınıfi & $\mathrm{Z} 2$ \\
\hline Spektrum Karakteristik Periyodu & $\mathrm{TA}=0.15 \mathrm{~TB}=0.40$ \\
\hline Ao (Etkin Yer İvmesi Katsayısı) & 0.2 \\
\hline
\end{tabular}

Tablo 4. Korkut Ata Lisesi'nin StatiCAD-Yı̆̆ma Programına Aktarılabilmesi için Gerekli Yük Kombinasyonları (TS 500,2000)

\begin{tabular}{|l|l|l|l|}
\hline Yük Kombinasyonları & $\begin{array}{l}\text { G } \\
\text { ( Ölü Yük) }\end{array}$ & Q (Hareketli Yük) & $\begin{array}{l}\text { E } \\
\text { (Deprem Yükü) }\end{array}$ \\
\hline $\begin{array}{l}\text { Basınç Gerilmesi için Yük } \\
\text { Kombinasyonu }\end{array}$ & 1.0 & 1.0 & 1.0 \\
\hline $\begin{array}{l}\text { Döşeme Betonarme Hesabı için } \\
\text { Kullanılan Yük Kombinasyonu }\end{array}$ & 1.4 & 1.6 & $\begin{array}{l}\text { HYKK } \\
\text { (Hareketli Yük } \\
\text { Katılım Katsayısı) }\end{array}$ \\
\hline $\begin{array}{l}\text { Kayma Gerilmesi Hesabı için } \\
\text { Kullanılan Yük Kombinasyonu }\end{array}$ & 1.0 & 1.0 \\
\hline
\end{tabular}

Tablo 5. Taşıyıcı Sistem Katsayıları (DBYBHY,2007)

\begin{tabular}{|l|l|}
\hline Bina Önem Katsayısı & 1.4 \\
\hline R (Taşıyıcı Sistem Davranış Katsayısı) & 2 \\
\hline ST (Spektrum Katsayısı) & 2.5 \\
\hline
\end{tabular}




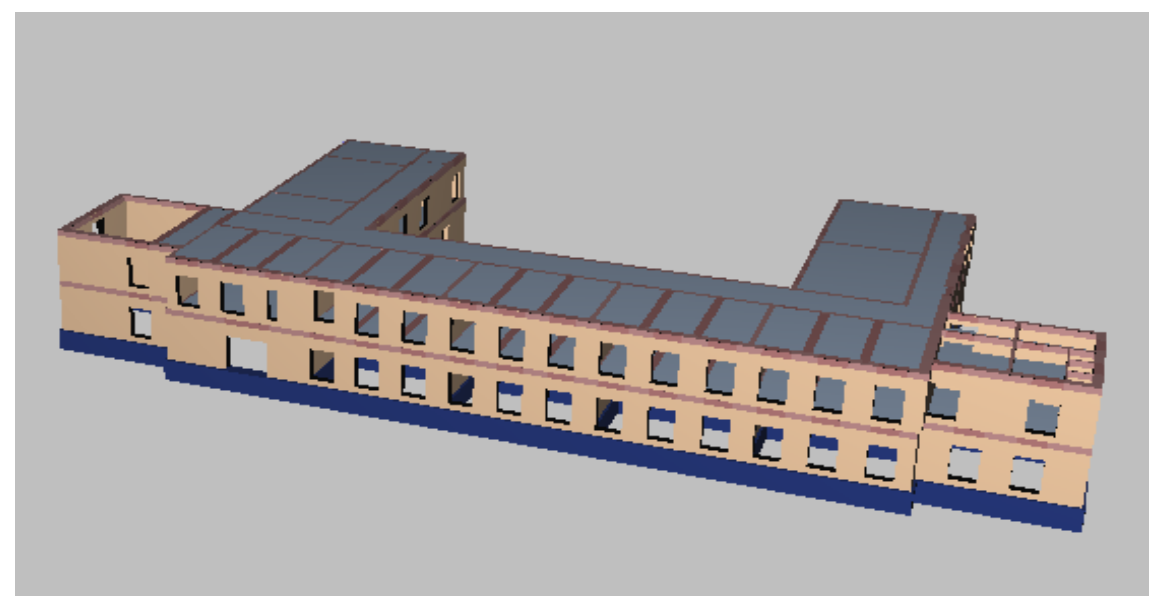

Şekil 6. Korkut Ata Lisesi'nin Üç Boyutlu Görüntüsü

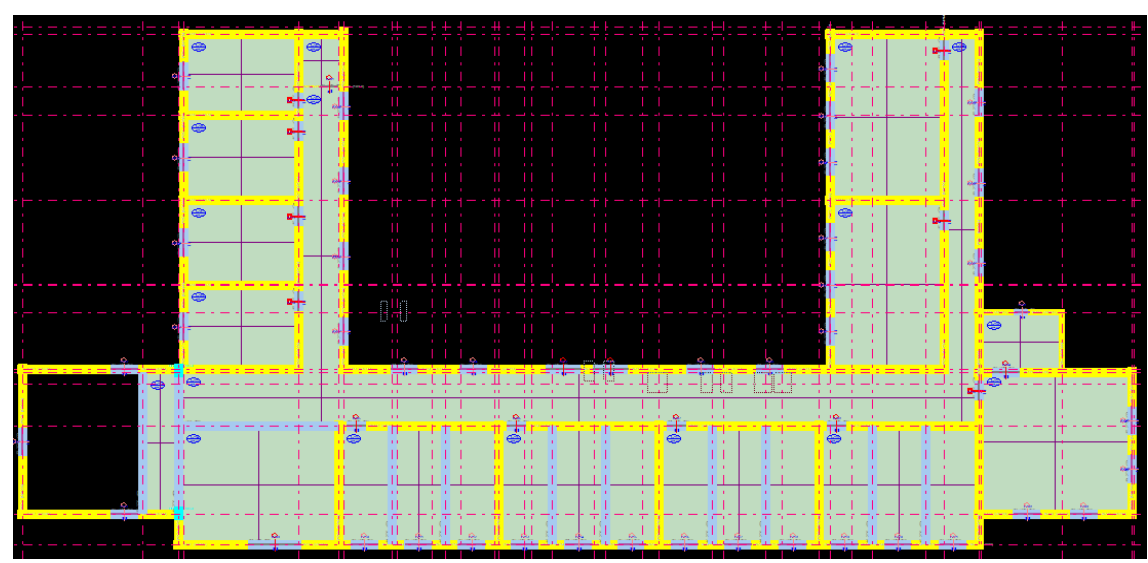

Şekil 7. Korkut Ata Lisesi’nin StatiCAD Yığma Programı Çizimleri (Zemin Kat)

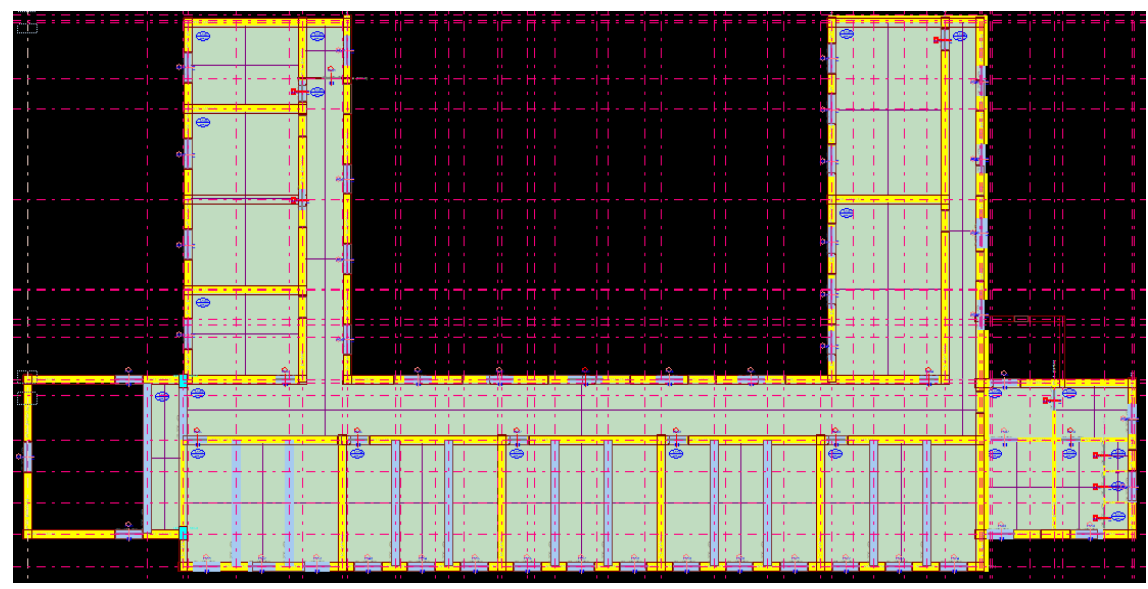

Şekil 8. Korkut Ata Lisesi’nin StatiCAD Yığma Programı Çizimleri (1. Kat)

Korkut Ata Lisesi'nin performans analizi yapılmadan önce analiz için 2007 Deprem Yönetmeliği seçilmiş, analiz öncesi orta bilgi düzeyine sahip olduğumuz bilgileri de programa girilmişti. 50 yılda aşılma olasılığ $\% 10$ olan depremler için, gerekli kabuller yapılarak yaptığımız hesaplar sonucunda, kayma gerilmesini sağlamayan yap1 elemanlarının, toplam kesme kuvvetlerine oranları sirası ile; zemin kat X-X yönünde, \%13.90, zemin kat $\mathrm{Y}-\mathrm{Y}$ yönünde, \%33.20, birinci kat $X-X$ yönünde, $\% 35.00$, birinci kat Y-Y yönünde \%55.10 olarak elde edilmiştir. 2007 Deprem Yönetmeliği'ne göre Korkut Ata Lisesi binasının göçme durumunda olduğu belirlenmiştir. Analiz özeti Tablo 6 ve Tablo 7'de verilmiştir. Analiz sonucunda basınç ve kayma gerilmelerini sağlamayan elemanlar Şekil 9 ve Şekil 10'da görülmektedir. 
Tablo 6. StatiCAD-Yığma Programı analiz sonuçları (1)

\begin{tabular}{|l|l|l|l|l|l|l|l|}
\hline \multicolumn{2}{|l}{ PERFORMANS RAPORU } \\
\hline \multirow{2}{*}{ Kat İsmi } & $\begin{array}{l}\text { Deprem } \\
\text { Yönü }\end{array}$ & $\mathbf{Q}_{\mathbf{i}}(\mathbf{t o n})$ & $\mathbf{e}(\mathbf{m})$ & $\mathbf{M b}_{\mathbf{i}}(\mathbf{t m})$ & $\begin{array}{l}\mathbf{Q t b}_{\mathbf{i}} \\
(\mathbf{t o n})\end{array}$ & $\begin{array}{l}\sum_{\mathbf{V}_{\mathbf{r}}}^{(\mathbf{D u v a r})} \\
(\mathbf{t o n})\end{array}$ & $\sum \mathbf{V}_{\mathbf{e}}(\mathbf{t o n})$ \\
\hline \multirow{2}{*}{$\begin{array}{l}\text { Zemin } \\
\text { Kat }\end{array}$} & $\mathrm{X}-\mathrm{X}$ & 989.79 & 2.93 & 2904.59 & 1032.11 & 1398.07 & 1032.11 \\
\cline { 2 - 8 } & $\mathrm{Y}-\mathrm{Y}$ & 989.79 & 0.99 & 977.31 & 1028.64 & 1057.40 & 1028.64 \\
\hline \multirow{2}{*}{ 1. Kat } & $\mathrm{X}-\mathrm{X}$ & 617.71 & 6.11 & 3774.26 & 660.73 & 751.97 & 660.73 \\
\cline { 2 - 8 } & $\mathrm{Y}-\mathrm{Y}$ & 617.71 & 2.02 & 1249.21 & 667.11 & 618.62 & 667.11 \\
\hline
\end{tabular}

Tablo 7. StatiCAD-Yı̆̆ma Programı analiz sonuçları(2)

\begin{tabular}{|l|l|l|l|l|l|l|l|}
\hline \multicolumn{2}{|l|}{ PERFORMANS RAPORU } \\
\hline \multirow{3}{*}{ Kat İsmi } & $\begin{array}{l}\text { Deprem } \\
\text { Yönü }\end{array}$ & $\begin{array}{l}\text { Yetersiz } \\
\begin{array}{l}\mathbf{V}_{\mathbf{r}} \\
\text { (ton) }\end{array}\end{array}$ & $\begin{array}{l}\text { Yetersiz } \\
\begin{array}{l}\mathbf{V}_{\mathbf{e}} \\
\text { (ton) }\end{array}\end{array}$ & $\sum \mathbf{W}_{\mathbf{a}}$ & $\sum \mathbf{W}_{\mathbf{n}}$ & $\begin{array}{l}\text { Yetersiz } \\
\sum \mathbf{V}_{\mathbf{r}}(\mathbf{t o n})\end{array}$ & $\begin{array}{l}\text { Yetersiz } \\
\sum \mathbf{V}_{\mathbf{r}}\end{array}$ \\
\hline \multirow{2}{*}{$\begin{array}{l}\text { Kemin } \\
\text { Kat }\end{array}$} & $\mathrm{X}-\mathrm{X}$ & 91.48 & 143.03 & 80.01 & 46 & 5 & 13.90 \\
\cline { 2 - 8 } & $\mathrm{Y}-\mathrm{Y}$ & 226.27 & 341.87 & 64.81 & 41 & 14 & 33.20 \\
\hline \multirow{2}{*}{ 1. Kat } & $\mathrm{X}-\mathrm{X}$ & 186.08 & 231.44 & 55.96 & 52 & 12 & 35.00 \\
\cline { 2 - 8 } & $\mathrm{Y}-\mathrm{Y}$ & 234.64 & 367.78 & 50.04 & 44 & 16 & 55.10 \\
\hline
\end{tabular}

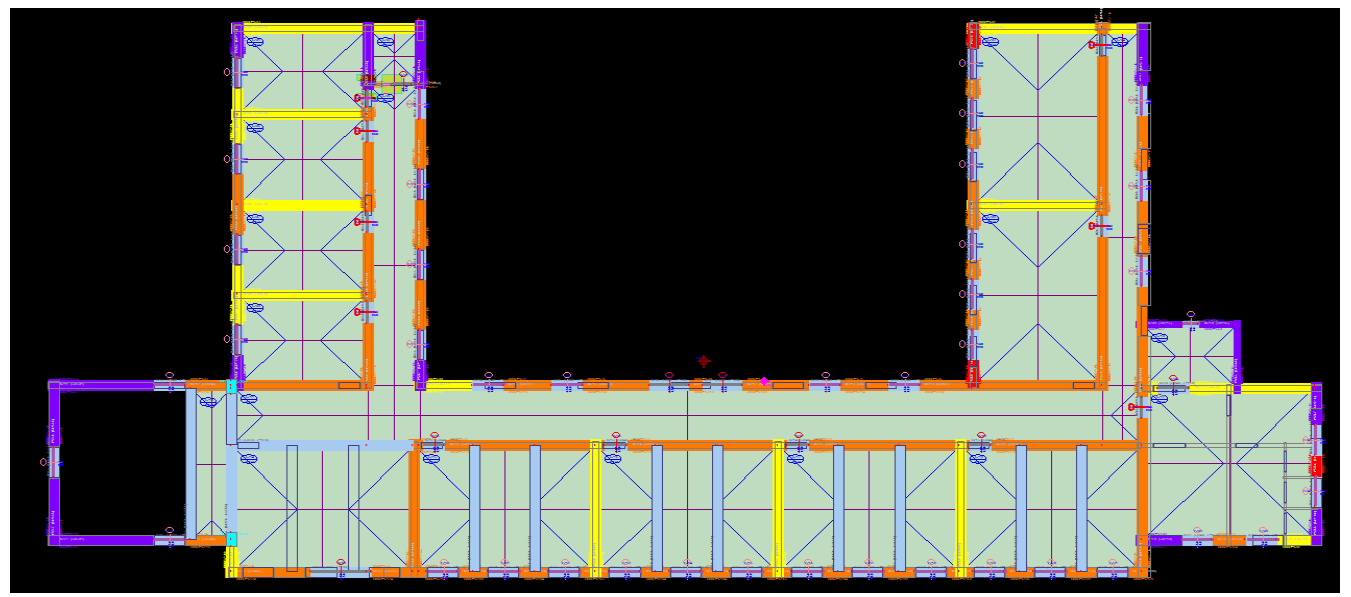

Şekil 9. Analiz sonucu zemin katta basınç ve kayma gerilmelerini sağlamayan elemanlar

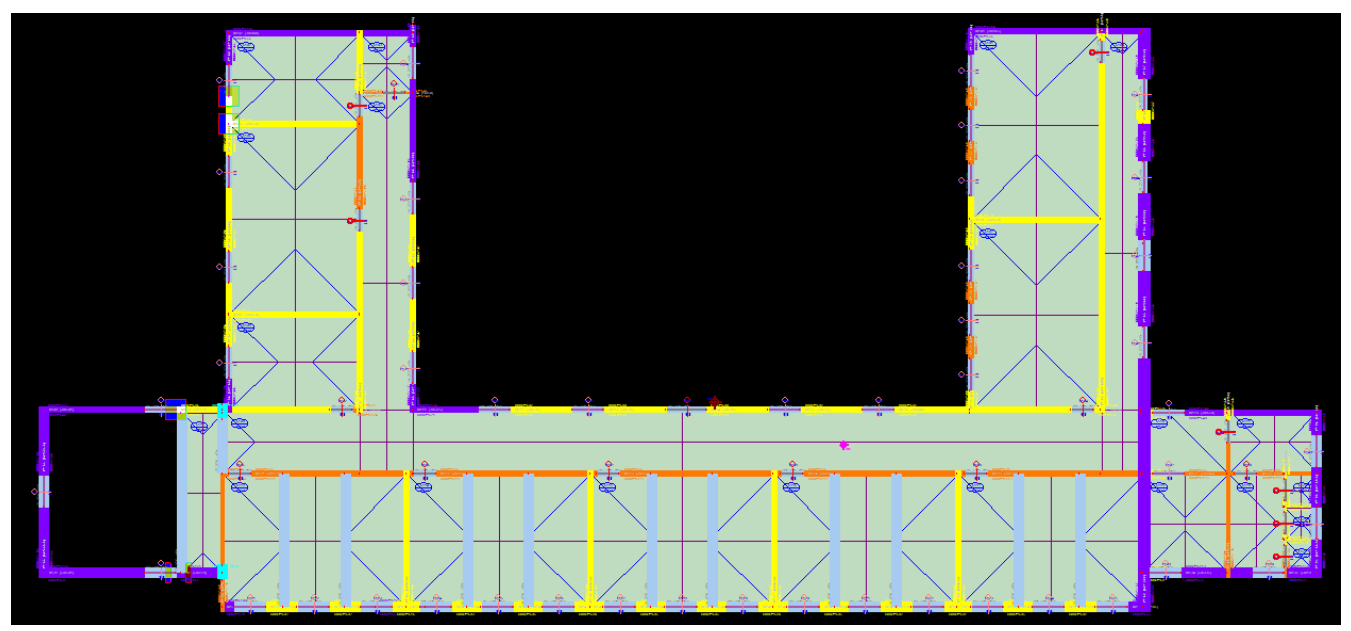

Şekil 10. Analiz sonucu birinci katta basınç ve kayma gerilmelerini sağlamayan elemanlar 


\section{Sonuçlar ve Öneriler}

Bu çalışmada Korku Ata Lisesi'nin 2007 Deprem Yönetmeliğine göre 50 yılda gerçekleşme ihtimali $\% 10$ olan depremlerde beklenen performans1 elde edilmeye çalışılmıştır. Bununla birlikte StatiCAD Yığma programında kullanılan yapı malzemesinin mekanik özellikleri literatürdeki benzer çalışmalardan referans alınmıştır. Bayburt doğal taşının gerçek mekanik özelliklerinin bilinmemesi, taş ve harcın tek bir malzeme gibi modellenmesinden dolayı analiz sonuçları kaba bir yaklaşımla elde edilmiştir.

- Zemin katta X-X yönünde 46 duvardan 5 tanesi yetersizdir. Y-Y yönünde 41 duvardan 14 ü yetersizdir. 1. Katta $X-X$ yönünde 52 duvardan 12 'si yetersizdir. Y-Y yönünde ise 44 duvardan 16's1 yetersizdir.

- Yetersiz olan duvarlar Şekil 10 ve Şekil 11'de farklı renklerde gösterilmiştir. Turuncu renk ile gösterilen duvarlarda basınç gerilmesi sağlanmamıştır. Mor renk ile gösterilen duvarlarda kayma gerilmesi sağlanmamıştır. Kırmızı renk ile gösterilen duvarlarda hem basınç hem de kayma gerilmesi sağlanmamıştır.

- 2007 Deprem Yönetmeliğine göre Korkut Ata Lisesi'nin bulunduğu bölge için hazırlanan davranış spekturumu verilerine göre hesap yapıldığında Korkut Ata Lisesi'nde meydana gelen basınç ve kayma gerilmelerinin literatürde alınan emniyet gerilmeleri değerlerinin altında olduğu yani, yapının göçme durumunda olduğu söylenebilmektedir.

Yapının iyileştirilmesi için taşıyıcı elemanlarda yani duvar ve hatıllarda güçlendirme yapılarak, göçmenin önüne geçilmesi gerektiği düşünülmektedir. Çalışmanın yapıldığı yığma yapının bir okul binası olması nedeniyle, yapılacak güçlendirme müdahalelerinin geciktirilmeden yapılmasının gerektiği düşünülmektedir. İlimizde bulunan yığma binaların 2007 Deprem Yönetmeliği dikkate alınarak deprem davranışları tespit edilmeli, gerekli durumlarda bu yapılara güçlendirme yapılmalıdır.

\section{Kaynaklar}

Aköz, A., H., 2008. Deprem Etkisi Altındaki Tarihi Yığma Yapıların Onarım ve Güçlendirilmesi, Yüksek Lisans Tezi, İstanbul Teknik Üniversitesi, Fen Bilimleri Enstitüsü, İstanbul.
Aköz, F. ve Yüzer, N., 2009. Tarihi Yapılarda Malzeme Özelliklerinin Belirlenmesinde Uygulanan Yöntemler, IMO- 1.İnşaat Mühendisliği Eğitimi Sempozyumu, Antalya.

Arıcan, Y., 2010. Yığma Yapıların Deprem Etkisi Altındaki Davranışı, Yüksek Lisans Tezi, Süleyman Demirel Üniversitesi, Fen Bilimler Enstitüsü, Isparta.

Arslan, A., 2016. Süleymaniye Camii'nin Yerel Zemin Koşullarına Bağlı Deprem Performansının Değerlendirilmesi, Yüksek Lisans Tezi, Yıldız Teknik Üniversitesi, Fen Bilimleri Enstitüsü, İstanbul.

Atabey, İ., 2011. Yığma Binaların Performans Analizi Sivas Suşehri Aşağısarıca İlköğretim Okulu Örneği, Yüksek Lisans Tezi, Gazi Üniversitesi, Fen Bilimler Enstitüsü, Ankara.

Can, H. ve Ünay., A.,İ., 2012. Tarihi Yapıların Deprem Davranışını Belirlemek İçin Sayısal Analiz Yöntemleri, Gazi Üniversitesi Mühendislik ve Mimarlık Fakültesi Dergisi, 27, 1, 211-217, Ankara.

Chamaky, R., Y., 2014. Tarihi Yığma Yapıların Deprem Analizi ve Uygun Güçlendirme Teknikleri, Yüksek Lisans Tezi, Yıldız Teknik Üniversitesi, İstanbul.

Çal, G. ve Şahin, A., 2015. Ortaköy Büyük Mecidiye Camii'nin Farklı Deprem Etkileri Altında Sismik Davranışııın Değerlendirilmesi, 5.Tarihi Eserlerin Güçlendirilmesi ve Geleceğe Güvenle Devredilmesi Sempozyumu, Erzurum.

Çobanoğlu, A.B., 2014. Türkiye'deki Yığma Binaların Malzeme Özelliklerinin İncelenmesi, Yüksek Lisans Tezi, Ortadoğu Teknik Üniversitesi, Fen Bilimler Enstitüsü, Ankara.

Dabanlı, Ö., 2008. Tarihi Yığma Yapıların Deprem Performansinin Belirlenmesi, Yüksek Lisans Tezi, Yıldız Teknik Üniversitesi, Fen Bilimleri Enstitüsü, İstanbul.

DBYBYHY, 2007. Deprem Bölgelerinde Yapılacak Binalar Hakkında Yönetmelik. 
Durutürk, G., 2012. Yalvaç Hamidiye Cami Deprem Analizi, Yüksek Lisans Tezi, Süleyman Demirel Üniversitesi, Fen Bilimleri Enstitüsü, Isparta.

Düzgün, O. A., Hatipoğlu, Y.,S., Artar, M., Yurdakul, M. ve Öner, E., 2015b. Ahmed-i Zencani Kümbetinin Sonlu Elemanlar Analizi İle Taşıyıcı Sistem Performansının Belirlenmesi, 5. Tarihi Eserlerin Güçlendirilmesi ve Geleceğe Güvenle Devredilmesi Sempozyumu, Erzurum.

Düzgün, O., A., Hatipoğlu, Y.,S., Artar, M., Yurdakul, M. ve Öner, E., 2015a. Zahit Efendi Camisi'nin Sonlu Elemanlar Analizi ile Taşıyıcı Sistem Performansının Belirlenmesi, Tarihi Eserlerin Güçlendirilmesi ve Geleceğe Güvenle Devredilmesi Sempozyumu, Erzurum.

Kılıç, İ., Çoşkun, H. ve Uslu, H., 2013. Hatay Hükümet Konağının Deprem Yükleri Etkisinde Davranışının İncelenmesi, 2.
Türkiye Deprem Mühendisliği ve Sismoloji Konferans1, Mustafa Kemal Üniversitesi, Hatay.

Riskli Bina Tespit Yönetmeliği, 2013.

Sallı, N., 2005. Mevcut Yı̆̆ma Yapıların Deprem Bakımından İncelenmesi ve Güçlendirilmesi, Yüksek Lisans Tezi, Pamukkale Üniversitesi, Fen Bilimleri Enstitüsü.

Sayın, E., 2009. Yığma Yapıların Lineer Olmayan Statik ve Dinamik Analizi, Doktora Tezi, Fırat Üniversitesi, Fen Bilimleri Enstitüsü, Elazığ.

TS 500, 2000. Betonarme Yapıların Tasarım ve Yapım Kuralları, TSE, Ankara.

Ünay, A., İ., 2002. Tarihi Yapıların Depreme Dayanımı, ODTÜ Mimarlık Fakültesi Basım İșliği, Ankara. 